\title{
Cytomorphological Patterns of Palpable Breast Lesions Diagnosed on Fine Needle Aspiration Cytology in Jimma Hospital, Ethiopia
}

\author{
Wondimu Abera \\ Adama General Hospital and Medical College \\ Dessie Abebaw Angaw \\ University of Gondar \\ Mesele Bezabih \\ Jimma University \\ Melkamu Tamir Hunegnaw ( $\square$ melkamutamir@gmail.com ) \\ University of Gondar
}

Research article

Keywords: Palpable Breast Lesions, Fine Needle Aspiration Cytology, Ethiopia

Posted Date: August 21st, 2020

DOI: https://doi.org/10.21203/rs.3.rs-62422/v1

License: (c) (i) This work is licensed under a Creative Commons Attribution 4.0 International License.

Read Full License 


\section{Abstract}

Background: Breast cancer is the most common cancer in women worldwide, in 2012 with nearly 1.7 million new cases were diagnosed. This represents about $12 \%$ of all new cancer cases and $25 \%$ of all cancers in women. In low and middle-income countries (LMCs), the infrastructure and resources for routine screening mammography are often unavailable.

Objective: The objective of this study focused on determining the cytomorphologic patterns of palpable breast lesions in Jima University Specialized Hospital.

Methods: A descriptive cross-sectional study was done on breast FNAC medical records. Analysis was done using SPSS version 20. Chi square test was applied to check the significant effect of independent variables on the dependent variables.

Result: In this study 735 patients were included and the overall distribution of the lesion was benign neoplastic $(51 \%)$, non-neoplastic $(28 \%)$, malignancy $(17 \%)$ and suspicious $(4 \%)$. The most common lesions in male were non-neoplastic and in female were benign neoplastic groups. The majority of (49.3\%) breast lesions were located in the left breast followed by right breast (43.9\%).

Conclusion: This study supports the usefulness of cytomorphological diagnostic techniques in the workout of breast lesions, confirms the predominance of benign breast lesions in the young and the occurrence of age independency in malignancy.

\section{Background}

Breast cells react to various stimuli and hormonal signals which display a range of appearances during puberty and reproductive life (1). Tissue of breasts is influenced by different hormones giving rise to various lesions (2).

Like other organs of human body breast can be affected by different kinds of diseases ranging from mild physiologic conditions to invasive cancers (3). Breast lumps are major surgical cases in both developed and developing countries (4).

Cancer is an uncontrolled proliferation of cells. GLOBOCAN, a project that study a global burden of cancers, in 2012, estimated 14.1 million new cancer cases and 8.2 million cancer related deaths compared with 2008 study which showed 12.7 million and 7.6 million respectively (5). Low and middleincome countries (LMC) lack resources for basic screening techniques like mammography. This is usually the main reason for the breast cancer diagnosis at a late stage. Inadequate treatment and higher mortality rates are another drawback in diagnosing breast cancers at later stages (5).

Hormonal medicines like contraceptives, hormonal therapy, and fat containing nutrients result in an increased risk of breast cancer. In 70\% of females with breast cancer the risk factor is not known. However, gender and age are the most significant risk factors for breast cancers (6). 
Different literatures reflected the third to fifth decade age and being females are prone to develop different types of breast cancers. For example, in India females and the majority cases lied between 40 to 50 years old, in Nepal 40 to 70 years old, in Kenya $90 \%$ of cases were females and the majority of them were in third and fourth decades, and in Ethiopia females and the fourth- and fifth-decade populations were more affected $(7,11,13,15)$.

For evaluation of malignancy or benign conditions of breast lesion cytological or pathological diagnosis is valuable (9). Fine needle aspiration (FNAC), scraping of skin (SS) and smearing of nipple discharge (ND) is the usual ways the breast lesions are investigated cytologically. FNAC is one component of triple assessment (the other two are clinical examination and mammography) of palpable breast lumps. It is an accurate, rapid, simple, cost effective and reproducible diagnostic tool $(8,10,14,16)$.

Therefore, the essence of this study was to illustrate the trends of palpable breast lesions diagnosed on fine needle aspiration cytology and its associated factors among women and men visiting Jimma Hospital, and to offer suggestions about some measures to put in place to reduce its morbidity and mortality.

\section{Methods}

\section{Study design, study setting and study period}

A cross-sectional study design was applied to all patients coming to Jimma University Medical Center (JUMC) pathology department. A laboratory with a palpable breast mass on which FNAC was performed from September 2014 to August 2017 in Jimma town; which is $353 \mathrm{~km}$ far from Addis Ababa the capital of Ethiopia.

\section{Study participants, sample size and sampling procedure}

All patients with palpable breast lesions subjected to FNAC at JUMC from September, 2014 to August, 2017 having age, sex and residency. FNAC cases of non-breast proper lesions, breast with secondary cancer, breast with recurrent breast cancer, breast with image guided, and breast with non-diagnostic or unsatisfactory report was excluded.

All cases fulfilling the inclusion criteria were included. FNAC breast cases containing pertinent history, general and local physical examination was retrieved and recorded from the pathology department data archive. The completeness of the data was checked. Cases were grouped on four diagnostic categories: Positive for malignancy, suspicious for malignancy, benign neoplastic and benign non-neoplastic.

\section{Plan for data collection and quality control}

The data were collected after permission was received from the medical director of the JUMC and after ethical clearance was obtained from the research and ethical committee of Jimma University. For data collection standard checklist was prepared which contained important parameters pertaining to the study. 
The data were collected by the Cytopathology technical staffs after training was given on how to locate, retrieve, categorize and record the data. The principal investigator supervised the data collectors through the data collection.

\section{Data management and analysis}

After appropriate coding, the collected data had been entered into epi data version 3.1 and it was exported to SPSS version 20 for analysis. Descriptive statistics like frequency, percentage and crosstabulation had been computed. Dependent variables and independent variables were entered into the chi square test in order to detect their significant association. A p-value less than 0.05 had been declared as significant statistical relationship dependent and independent variable in the chi square test. Variables like socio-demographic characteristics (Age, Sex and Resident), laterality of the mass, quadrant of the mass, positive for malignancy, suspicious for malignancy, benign neoplastic and non-neoplastic were included.

\section{Result}

In this study 735 patients were included with a mean age of $31.5 \pm 12.3$ years, which ranges 9 to 89 years old. Among all cases, 71(9.7\%) were male and 664 (92.3\%) were female patients. The most common lesions in male were non-neoplastic and in female were benign neoplastic groups (Fig. 1).

The most affected age group by malignancy was $31-40$ years. Using chi square test there was no significant association between increasing age ( $P$ value was 0.999$)$ and sex ( $P$ value- 0.325 ) as to rate of malignancy (Table 1).

Table 1

Lesions Distribution by Age Group at Jimma university medical center from 2014-2017

\begin{tabular}{|llllll|}
\hline \multirow{2}{*}{ Age Groups } & Lesions & & & \multicolumn{2}{c}{ Total } \\
\cline { 2 - 5 } & Malignancy & Suspicious & Benign Neoplastic & Non-Neoplastic & \\
\hline Under 10 & 0 & 0 & 2 & 1 & 3 \\
\hline $11-20$ & 3 & 2 & 110 & 26 & 141 \\
\hline $21-30$ & 25 & 7 & 171 & 91 & 294 \\
\hline $31-40$ & 42 & 9 & 71 & 47 & 169 \\
\hline $41-50$ & 33 & 4 & 19 & 16 & 72 \\
\hline $51-60$ & 14 & 3 & 4 & 17 & 38 \\
\hline $61-70$ & 3 & 3 & 1 & 5 & 12 \\
\hline$>=71$ & 3 & 0 & 0 & 3 & 6 \\
\hline Total & 123 & 28 & 378 & 206 & 735 \\
\hline
\end{tabular}




\section{Residency distribution}

The collected data over the three years showed $523(71.2 \%)$ patients from rural and $212(28.8 \%)$ patients from urban areas. The most and least common lesions in urban and rural were similarly shared, that were benign neoplastic cases and suspicious cases respectively. As for the relationship of malignancy and area of residency no strong association was seen ( $P$ value was 0.211 ).

\section{Laterality distribution of breast lesions}

In $323(43.9 \%)$ cases, the lesions were located in the right breast and in 362(49.3\%) cases these were located in the left breast. In 50(6.8\%) cases, bilateral lesions were observed. Left breast was more commonly affected by all breast lesions than the right breast. There was one suspicious case which affected both breasts while malignancy was not seen to affect both breasts. No significant association was seen between the rate of malignant and laterality ( $P$ value was 0.945 ).

\section{Quadrant distribution of breast lesions}

Among 735 cases, 553 (75.2\%) cases were correctly labeled for quadrants, and the mass was located in the upper outer quadrant in 206(37.3\%) cases, in the central region in $262(47.4 \%)$ cases, in the upper inner quadrant in $45(8.1 \%)$ cases, in the lower outer quadrant in 18 (3.3\%) cases and in the lower inner quadrant in 22 (3.9\%) cases. There was no significant association seen between rate of malignant and quadrant distribution ( $p$ value $=0.286$ ).

The cytological diagnoses included malignancy $123(16.7 \%)$, suspicious $28(3.8 \%)$, benign neoplastic 378 (51.4\%), and non-neoplastic 206 (28\%) cases (Fig. 2). Among benign neoplastic lesions, the two maximum cases were fibroadenoma $152(40.2 \%)$ and fibrocystic changes 117 (31.0\%), and the minimum cases were oncocytoma and papilloma (Table 2).

Table 2

Benign Neoplastic Lesions of patients at Jimma University medical center from 20142017

\begin{tabular}{|l|l|l|}
\hline Benign Neoplastic Group & Frequency & Percent \\
\hline Fibroadenoma & 152 & 40.2 \\
\hline FCC & 117 & 31.0 \\
\hline Benign Phyloides Tumor & 9 & 2.4 \\
\hline Lactating Adenoma & 8 & 2.1 \\
\hline Lipomatous Lesion & 13 & 3.4 \\
\hline Proliferative Lesions, NOS & 66 & 17.5 \\
\hline Ductal Hyperplasia & 11 & 2.9 \\
\hline Oncocytoma & 1 & 0.3 \\
\hline Papilloma & 1 & 0.3 \\
\hline Total & 378 & 100.0 \\
\hline
\end{tabular}

Among non-neoplastic lesions, the top maximum cases were that of chronic mastitis $52(25.2 \%)$ and Gynecomastia 41 (19.9\%). Abscess and cyst were found in 38 (18.4\%) and $37(18.0 \%)$ cases respectively. Acute mastitis was found in $17(8.3 \%)$ cases and $8(3.9 \%)$ cases were that of duct ectasia (Table 3$)$. 
Table 3

Non-Neoplastic Lesions of patients at Jimma University medical center, 2014-2017

\begin{tabular}{|l|l|l|}
\hline Non-Neoplastic Group & Frequency|Percent \\
\hline Acute Mastitis & 17 & 8.3 \\
\hline Chronic Mastitis & 52 & 25.2 \\
\hline Abscess & 38 & 18.4 \\
\hline Cyst & 37 & 18.0 \\
\hline Gynecomastia & 41 & 19.9 \\
\hline Duct Ectasia & 8 & 3.9 \\
\hline Fat Necrosis & 3 & 1.5 \\
\hline TB & 6 & 2.9 \\
\hline Lactational Change & 2 & 1.0 \\
\hline Fibroepithelial Polyp & 1 & 0.5 \\
\hline Intramammary Lymphadenitis & 1 & 0.5 \\
\hline Total & 206 & 100.0 \\
\hline
\end{tabular}

Gynecomastia was the most common disease that affected male and chronic mastitis the female. All cases of tuberculosis, fat necrosis and intramammary lymphadenitis were seen in female. A single case of fibroepithelial polyp was found in male.

From a total of 123 malignant cases, $90(73.2 \%)$ cases were having lymph nodes and from malignant cases with lymph nodes $83(92.2 \%)$ cases were positive for malignant cells and 7 (7.8\%) were negative for malignant cells.

\section{Discussion}

Of 735 breast lesions malignancy was seen in 123 cases, of which 90 (73.2\%) cases were accompanied by lymph node enlargements and a majority of them 83 (67.5\%) were positive for malignant cells. Lymph node assessment is important in breast lesion evaluation for correct management and prognostications. Cases were observed more on the left and the central region of the breast. This study also showed majority of patients were from rural, female was affected more frequently than male, and the patients were concentrated in 31 to 40-year age group. This finding is in accordance with the study done in developing country (3).

The diagnosis of suspicious is rendered when in an atypical cytological smear there is no strong evidence of malignancy. In this study there was a record of 28 (3\%) suspicious cases over the three years of the study period. An inter observer differences in interpretation of cytology smear are always there. Nevertheless histopathology is the next investigation to delineate the diagnostic category. This finding was supported by the study done in Thailand (31/190) (3).

Benign neoplastic groups (378/735) have nine disease entities. The three most common lesions were fibroadenoma observed in $152(40.2 \%)$ cases, fibrocystic changes $117(31.0 \%)$ case and proliferative lesions, NOS in $66(17.5 \%)$ cases. Papilloma and oncocytoma were seen with equal frequency (one case each). In this study, patients from both rural and urban were mostly affected by diseases from this group than other disease categories. The female was more affected than male. Similar conclusions were made from the studies done in India, Pakistan and Eastern Nepal $(8,11$, and 12). 
Under non-neoplastic group of lesion males were more frequentlyaffected than other three categories of lesions. Patients from rural and the age group of 21 to 30 years were more commonly affected by these diseases. The left breast was affected more frequently than the right one. The majority of cases were aggregated in the central region of the breast. The three top diseases in this category were chronic mastitis 52 (25.2\%) cases, Gynecomastia 41 (19.9\%) cases and Abscess $38(18.4 \%)$ cases. Similar finding was seen in the Indian study $(4,8)$. The non-neoplastic diseases do not have the risk of malignancy.

\section{Conclusion}

In conclusion, this study supports the usefulness of cytomorphological diagnostic techniques in the workout of breast lesions, confirms the predominance of benign breast lesions in the young and the occurrence of age independency in malignancy.

\section{Limitations}

The possible limitations of this study may be the inter-observer subjectivity that exists during the interpretation of the smears was always considered, and this was reduced by agreement of the cytopathologists on diagnostic cytomorphologic criteria, histopathologic confirmation on disease patterns was not done and being a retrospective study there was incompleteness in data collection.

\section{Abbreviations}

\section{FNAC}

fine needle aspiration; JUMC:Jimma University Medical Center; LMC:Iow and middle-income countries; ND:nipple discharge; SS:scraping skin

\section{Declarations}

\section{Ethics approval and consent to participate data}

Before the study begins ethical clearance was obtained from the research and ethical committee of Jimma University. Permission was received from medical director of the Jimma University medical college.

\section{Availability of data and materials}

The datasets used and/or analyzed during the current study are availablefrom thecorresponding author on reasonable request.

\section{Consent to publish}

Not applicable. 


\section{Competing interest}

No potential conflict of interests with respect to the research, authorship and/or publication of this article.

\section{Authors' contribution}

WA, DA, MB and MTH conceived of the study and were involved in design of the study, in the coordination and reviewed the article, analysis, report writing and drafted the manuscript. All authors read and approved the final manuscript.

\section{Authors' Information}

WA is pathologist, DA biostatistician and epidemiologist and $\mathrm{MB}$ is associate professor of pathology and epidemiologist and MTH Radiological technologist and nutritionist.

\section{Acknowledgments}

We would like to thank the Jimma University for Ethical Approval. We also like to extend our appreciation to data collectors.

\section{Funding}

This research work was funded by Jimma university medical center from design to report writing.

\section{References}

1. Rosai J. Rosai and Ackerman's surgical pathology e-book. Elsevier Health Sciences; 2011 Jun 20.

2. Kumar R. A clinicopathologic study of breast lumps in Bhairahwa, Nepal. Asian Pac J Cancer Prev. 2010 Jan 1;11(4):855-8

3. Wadie M. Elmadhoun, M., \& Ahmed O. Almobarak, M. Cytomorphology of Palpable breast lesion. Diagnostic Cytopathology,2015;1-5.

4. Ghanghoria S, Soni S, Patidar H, Likhar K. Pattern of palpable breast lesions on fine needle aspiration cytology: a retrospective and prospective analysis of 1,000 cases. International Journal of Medical Science and Public Health. 2016 Jan 1;5(1):97-101.

5. Cotran, Robin. A. (2015). Pathologic Basis of Disease. Philadelphia: ELSEVIER

6. Eble JN, Tavassoli FA, Devilee P, editors. Pathology and Genetics of Tumours of the Breast and Female Genital Organs. Iarc; 2003.

7. Abate Y, Yilma Z, Assefa M, Tigeneh W. Trends of breast cancer in Ethiopia. Int J Cancer Res Mol Mech. 2016;2:1-5.

8. Singh P, Chaudhry M, Nauhria S, Rao D. Cytomorphological patterns of breast lesions diagnosed on fine-needle aspiration cytology in a tertiary care hospital. Int J Med Sci Public Health. 2015 May 1;4(5):674-9. 
9. Kocaay AF, Celik SU, Sevim Y, Ozyazici S, Cetinkaya OA, Alic KB. The role of fine needle aspiration cytology and core biopsy in the diagnosis of palpable breast masses. Nigerian medical journal: journal of the Nigeria Medical Association. 2016 Mar;57(2):77.

10. Pereira EM, Tambekar MY, Sahu S, Dhar R. Diagnostic efficacy of fine needle aspiration cytology in breast lesions,2009; 10(2): 623-626

11. Bukhari MH, Arshad M, Jamal S. Use of Fine Needle Aspiration in the Evaluation of Breast lumps Pathology. Research International. 2011.

12. Singh M, Kafle SU, Jha KK. Cytological Study of Palpable Breast Lump Presenting in Eastern Nepal. Birat Journal of Health Sciences. 2016;1(1):27-32.

13. Naik P. Cytomorphological study of palpable benign breast lesions. International Journal of Research in Medical Sciences. 2017 Apr 26;5(5):1843-5.

14. Nkonge KM., Rogena E A \& Nkonge EO.Cytological evaluation of breast lesions in symptomatic patients presenting to Kenyatta National Hospital, Kenya: a retrospective study. BMC Women's Health.2015 (15); 118-124

15. Bezabih M. Superficial malignant neoplasms in southwestern Ethiopia: a cytopathological approach. Diagnostic cytopathology. 2004 Nov;31(5):347-51.

16. Almobarak AO, Elhassan TM, Elhoweris MH, Awadalla HM, Elmadhoun WM, Ahmed MH. Cytomorphologic patterns of breast lesions in Sudanese patients: lessons learned from fine needle aspiration cytology. Asian Pacific Journal of Cancer Prevention. 2014;15(8):3411-3.

\section{Figures}




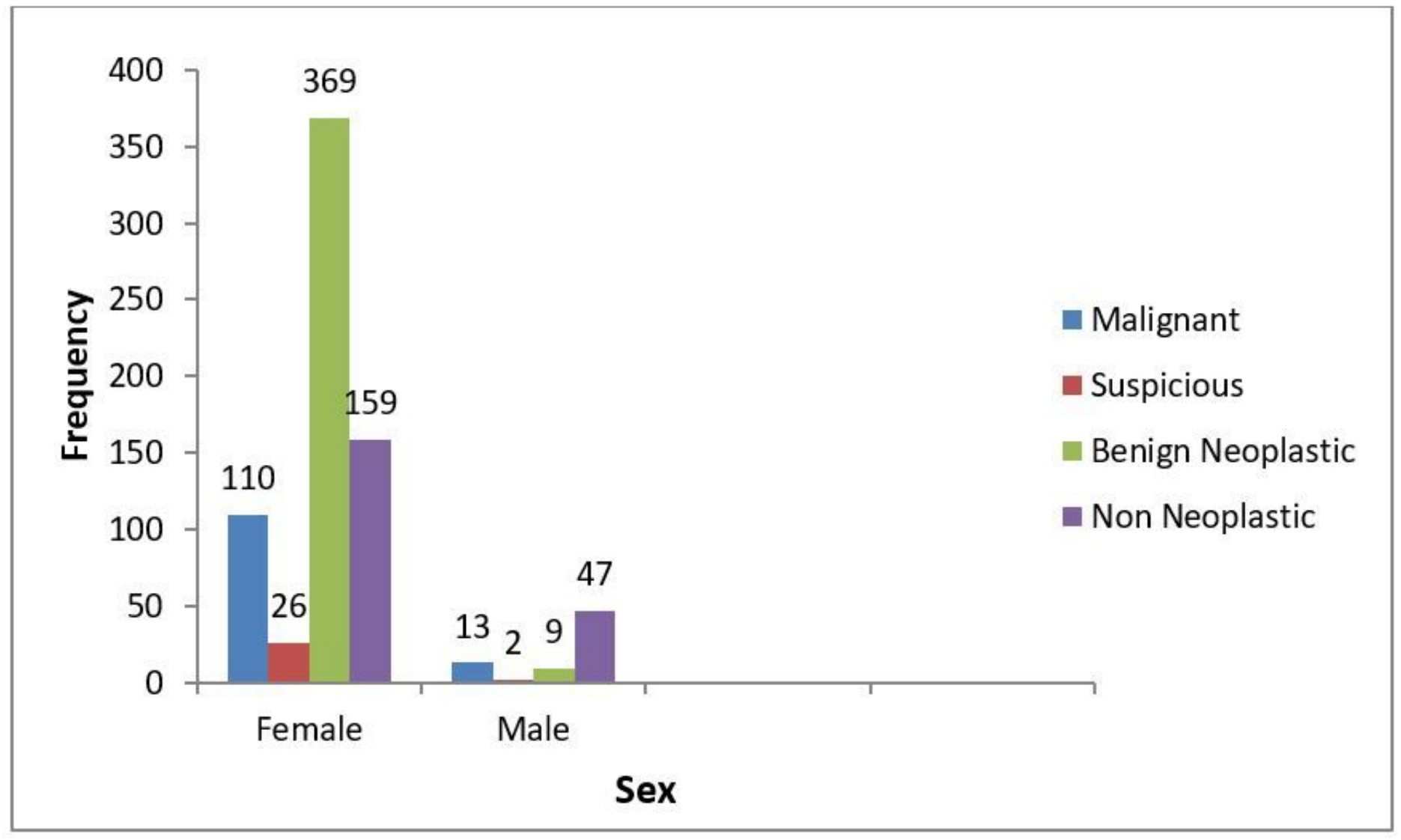

Figure 1

Lesion distribution by sex at Jimma Medical Center from 2014-2017 


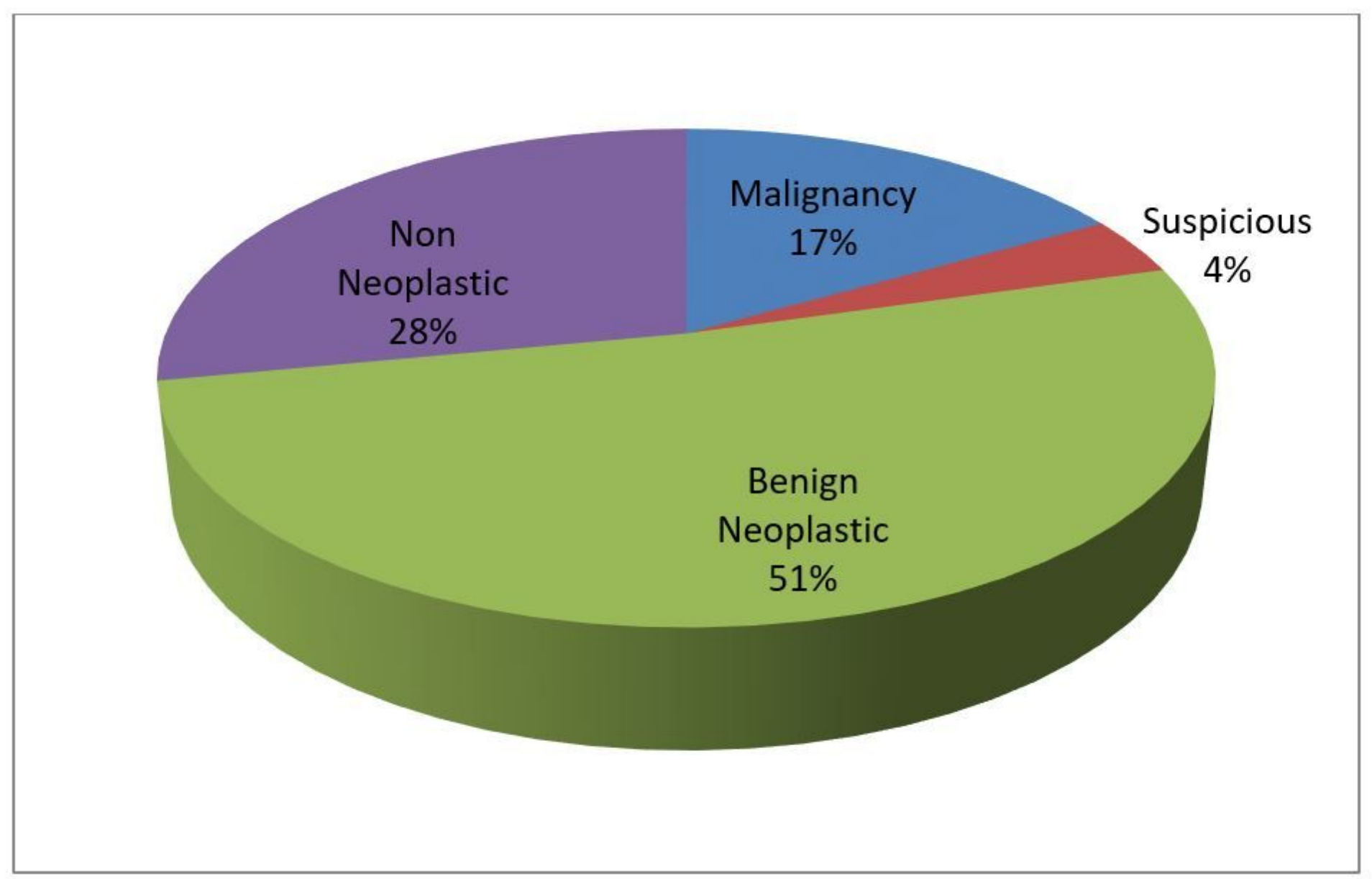

Figure 2

Percentage of Lesions types at Jimma university medical center from 2014-2017 